\title{
Fertilization and Tree Density Effects on Cellulose Decomposition in a Larix leptolepis Plantation
}

\author{
Kim, Choonsig*, Oue-Ryong Kim, Hyun-Chul Ahn, Hyun-Seo Cho, \\ Gab-Chul Choo and Jae-Hyeon Park \\ Department of Forest Resources, Jinju National University, Jinju 660-758, Korea
}

\begin{abstract}
Cellulose mass loss by cellulose filter papers was measured for 3 time ( 35 days, 70 days, 105 days) incubation during the growing season (from May to September 2002) with different tree density and after fertilization in a Japanese larch (Lanix leptolepis) plantation. Cellulose mass loss rates were significantly different between tree density types and fertilization treatments during the study periods. After 105 day incubation of cellulose filter paper, cellulose mass loss rates were significantly higher in the low tree density $(70.1 \%)$ than in the high tree density $(49.9 \%)$. Cellulose mass loss rates averaged $62.8 \%$ in the fertilization and $58.9 \%$ in the unfertilization treatments during the same periods. However, cellulose mass loss was not significantly different between the forest floor and the mineral soil layer except for 35 day incubation. The results indicate that cellulose decomposition rates are a useful index to express differences in organic matter decomposition activity in different tree density and after fertilizer treatments.
\end{abstract}

Key words: Cellulolytic activity, Decomposition, Fertilization, Larch, Tree density

\section{INTRODUCTION}

Organic matter decomposition is one of the key processes in nutrient dynamics of forest ecosystem. The decomposition rates in soils determine the available nutrients indicating high fertility with a high rate of organic matter decomposition (Binkley 1984 , Haraguchi et al. 2002, Kim 2000). Organic matter decomposition rates have been related to many factors, including macro- and micro-climate (Meentemeyer 1978, Yin et al. 1989), litter quality (Fogel and Cromack 1977), slope and azimuth (Lousier and Parkinson, 1976), abundance of microbial communities (Blair et al. 1990), and canopy cover rates and nitrogen availability (Kim 2000). The use of cellulose fiter paper, which can eliminate substrate variation resulting from litter quality, allows useful comparisons of relative cellulose mass loss rates between treatments or sites (Yin et al. 1989, McClellan et al. 1990). The difference in cellulose decomposition rates among forest types is controlled by several factors, including soil physical and chemical properties, soil temperature, and earthworm activity (Piene and Van Cleve 1983, Brown and Howson 1988, Beyer 1992). Generally, the cotton strip method has been used for assessment of cellulose decomposition rates in soil profiles (French and Howson 1982, Hill et al. 1985), but cellulose filter paper is also used because it is a simple and easy method (Binkley 1984, McClellan et al. 1990, Kim 2000, Haraguchi et al. 2002).
Although several studies have reported on the cellulose decomposition rates after canopy removal (Binkley 1984, Mader et al. 1989, Kim 2000) and among vegetation types (Conn and Day 1996, Haraguchi et al. 2002), the direction and rates of change associated with tree density and fertilization in a Japanese larch plantation, which was a major tree planting species in Korea, are not well understood. Consequently, the objectives of this study were to measure tree density and fertilization effects on cellulose decomposition rates in the forest floor and mineral soil layer in a Japanese larch plantation.

\section{MATERIALS AND METHODS}

\section{Study site and experimental design}

The study was conducted in the Sambong exhibition forests located in Hamyang-gun, Gyungsangnam-do administered by Seobu National Forest Office. Annual precipitation in this area averages $1,322 \mathrm{~mm} / \mathrm{yr}$ and annual average temperature is 12.8 ${ }^{\circ} \mathrm{C}$. Experimental plots were located in two adjacent Japanese larch plantations on moderately productive upland sites (Site Index 15). Mean stand age was about 35 years. The Japanese larch plantations were situated within about $1,000 \mathrm{~m}$ of each other. The experimental design consisted of two tree density treatments (high tree density and low tree density), and each tree

\footnotetext{
*Author for correspondenœ; Phone: 82-55-751-3247, Fax: 82-55-751-3241, e-mail: ckim@chinju.ac.kr
} 
density treament divided into eight $20 \mathrm{~m} \times 10 \mathrm{~m}$ plots randomly assigned four fertilization and four unfertilization plots with leaving an $5 \mathrm{~m}$ buffer zone among each plot. Fertilizers were manually applied on the forest floor surface in the spring (24 May, 2002). Urea, fused and superphosphate, and potasium chloride were used as sources of $N, P$ and $K$, respectively, at the rate of 112 $\mathrm{kg} / \mathrm{ha}$ for $N, 75 \mathrm{~kg} / \mathrm{ha}$ for $P$ and $37 \mathrm{~kg} / \mathrm{ha}$ for $K$.

The volumetric soil water content was measured by HydroSence (Campbell Scientific Australia Pty. Ltd.) with soil probe of $12 \mathrm{~cm}$ length. Soil temperature was measured by EGM-4 (PP systems) connected with soil probe of $20 \mathrm{~cm}$ length.

\section{Cellulose decomposition}

Cellulose filter papers were used for comparisons of relative cellulose decomposition rates between fertilizer treatment (fertilization and unfertilization), depth (forest floor and mineral soils), and tree density type (high and low tree density). Ashless cellulose filter papers (ADVANTEC No. 2, 15cm diameter, about 11g) were weighed to the nearest $0.01 \mathrm{~g}$ and placed into each numbered $15 \mathrm{~cm} \times 15 \mathrm{~cm}$ fiber glass bag (mesh size $1.5 \mathrm{~mm}$ ). Subsamples from each box of filter paper were also taken to determine oven-dried mass at $60^{\circ} \mathrm{C}$ for 48 hours

Nine bags ( 3 collection times $\times 3$ replicates) from each plot were placed horizontally at the interface of forest floor (Oa layer) and the mineral soil (the top of $A$ horizon) within fertilization and unfertilization treatments of each tree density type (24 May 2002). A sharp knife was used to minimize disturbance between the forest floor and the mineral soils. The same number of bags beside the cellulose bag placed in the forest floor to reduce the effects of site environmental variation were inserted vertically into the mineral soil to a depth of $15 \mathrm{~cm}$ with a straight-blade shovel. The bags were collected on three occasions ( 35 days, 70 days, 105 days incubations) during the 2002 growing season (from May to September). Collected filter papers were oven-dried at 60 $C$ for 48 hours, cleaned by gentle brushing with a soft paintbrush to remove mineral soil or fine-root residue on the surface, and weighed to determine cellulose mass loss rates.

The percent cellulose remaining mass $(Y)$ was calculated using the following equation: $Y=W_{a} W_{i} \times 100$

Where $W_{i}$ is the initial cellulose mass and $W a$ is the dry mass after removal from the field. Cellulose mass loss rates $(R)$ were calculated as $R=100-Y$

\section{Data analysis}

The study employed a split plot design for fertilizer treatments within each tree density type. In this design, all factors (fertilizer treatment, tree density type, depth) were fixed factors. Homogeneity of variances was tested using the Hartley test, and normal probability plots examined to test for normality of residuals (Neter et al. 1990). All percent data were transformed by the arcsine to stabilize variances and analyses of variance for the data were executed with the General Linear Models procedure in SAS (SAS Institute Inc. 1989).

\section{RESULTS AND DISCUSSION}

Tree density in the study site was 556 trees/ha in the high and 394 trees/ha in the low tree density plots. Both tree density plots show similar mean tree height, but mean diameter at breast height (DBH) was higher in the low tree density plots $(25.09 \mathrm{~cm})$ than in the high tree density plots $(21.44 \mathrm{~cm})$. The depth and mass of forest floor were also higher in the high than in the low tree density plots (Table 1). The fertilization plots showed similar tree density, mean height, mean DBH, and mass of forest floor, but the depth of forest floor was higher in the fertilization than the unfertilization plots (Table 1). Initial soil property of the study sites was similar between the high and the low tree density plots, and between the fertilization and the unfertilization plots (Table 2).

Cellulose decomposition rates were significantly different in the tree density types $(P<0.05)$ for three sampling times and in the fertilization treatments $(P<0.05)$ except for 105 day incubation (Table 3). Cellulose decomposition rates were significantly higher in the low than in the high tree density plots for three samping times. Cellulose filter papers in the low tree density plots lost $70.1 \%$ of the original dry mass compared with $49.9 \%$ in the high tree density for 105 days incubation (Fig. 1). Increased cellulose mass loss in the low tree density may due to the difference of soil temperature rather than the difference of soil water content. Soil water content was not consistent for the two sampling times between both tree density plots (Table 4). There was also no significant difference between soil property of the tree density types.

Table 1 General characteristics of the study sites (mean $\pm S D, n=8$ )

\begin{tabular}{|c|c|c|c|c|}
\hline & \multicolumn{2}{|c|}{ Tree density } & \multicolumn{2}{|c|}{ Fertilizer } \\
\hline & High & Low & Fertilization & Unfertilization \\
\hline Trees/ha & 556 & 394 & 456 & 487 \\
\hline Mean height(m) & $20.17 \pm 2.44$ & $21.5 \pm 1.41$ & $20.74 \pm 1.74$ & $20.90 \pm 2.53$ \\
\hline Mean DBH(cm) & $21.44 \pm 4.48$ & $25.09 \pm 3.88$ & $22.92 \pm 4.77$ & $23.01 \pm 5.21$ \\
\hline Depth of forest floor(cm) & $3.80 \pm 1.62$ & $3.48 \pm 1.19$ & $3.32 \pm 1.32$ & $3.95 \pm 1.50$ \\
\hline Mass of forest floor $\left(\mathrm{g} / 200 \mathrm{~cm}^{2}\right)$ & $29.96 \pm 9.54$ & $22.39 \pm 6.00$ & $23.98 \pm 10.05$ & $24.9 \pm 5.79$ \\
\hline
\end{tabular}


Table 2. Soil property of the study sites (mean $\pm S D, n=8$ )

\begin{tabular}{|c|c|c|c|c|c|c|c|c|c|c|c|}
\hline \multirow{3}{*}{\multicolumn{2}{|c|}{ Treaterment }} & \multirow{3}{*}{$\begin{array}{c}\text { Soil } \\
\text { Texture }\end{array}$} & \multirow{3}{*}{$\begin{array}{c}\mathrm{pH} \\
\left(1: 5 \mathrm{H}_{2} \mathrm{O}\right)\end{array}$} & \multirow{3}{*}{$\begin{array}{c}C \\
(\%)\end{array}$} & \multirow{3}{*}{$\begin{array}{l}\mathrm{TN} \\
(\%)\end{array}$} & \multirow{3}{*}{$\begin{array}{c}\text { Avail. } \\
\mathrm{P}_{2} \mathrm{O}_{5} \\
\text { (mg/kg) }\end{array}$} & \multirow{3}{*}{ CEC } & \multicolumn{4}{|c|}{ Exchangeable } \\
\hline & & & & & & & & $\mathrm{K}^{+}$ & $\mathrm{Na}^{+}$ & $\mathrm{Ca}^{2+}$ & $\mathrm{Mg}^{2+}$ \\
\hline & & & & & & & & & & (cm & $\mathrm{c} / \mathrm{kg})$ \\
\hline \multirow{2}{*}{$\begin{array}{c}\text { Tree } \\
\text { density }\end{array}$} & High & SiL & $4.70 \pm 0.21$ & $7.10 \pm 1.12$ & $0.42 \pm 0.06$ & $24 \pm 7.7$ & $19.8 \pm 1.3$ & $0.51 \pm 0.06$ & $0.14 \pm 0.01$ & $1.65 \pm 0.89$ & $0.62 \pm 0.17$ \\
\hline & Low & SiL & $5.00 \pm 0.18$ & $6.89 \pm 1.35$ & $0.44 \pm 0.08$ & $13 \pm 4.47$ & $22.0 \pm 1.18$ & $0.51 \pm 0.07$ & $0.14 \pm 0.01$ & $2.44 \pm 1.00$ & $0.83 \pm 0.28$ \\
\hline \multirow{2}{*}{ Fertilizer } & $\begin{array}{l}\text { Fertil- } \\
\text { ization }\end{array}$ & SiL & $4.80 \pm 0.27$ & $7.19 \pm 1.65$ & $0.42 \pm 0.08$ & $20 \pm 9.99$ & $20.1 \pm 1.56$ & $0.52 \pm 0.05$ & $0.15 \pm 0.01$ & $1.89 \pm 0.80$ & $0.74 \pm 0.22$ \\
\hline & $\begin{array}{l}\text { Unfertil } \\
\text {-ization }\end{array}$ & SiL & $4.90 \pm 0.22$ & $6.80 \pm 0.54$ & $0.43 \pm 0.07$ & $17 \pm 6.82$ & $21.0 \pm 1.81$ & $0.51 \pm 0.08$ & $0.14 \pm 0.01$ & $2.20 \pm 1.20$ & $0.71 \pm 0.26$ \\
\hline
\end{tabular}

Table 3. Analysis of variance of cellulose remaining mass

\begin{tabular}{|c|c|c|c|c|}
\hline Source of variation & df & ss & $\mathrm{F}$ & $p$ \\
\hline \multicolumn{5}{|l|}{35 days incubation } \\
\hline Tree density $(T)$ & 1 & 0.1939 & 17.50 & 0.0001 \\
\hline Depth(D) & 1 & 0.8131 & 73.38 & 0.0001 \\
\hline Fertilization $(F)$ & 1 & 0.2750 & 24.81 & 0.0001 \\
\hline$T \times D$ & 1 & 0.0760 & 6.85 & 0.0104 \\
\hline $\mathrm{T} \times \mathrm{F}$ & 1 & 0.0004 & 0.04 & 0.8475 \\
\hline $\mathrm{D} \times \mathrm{F}$ & 1 & 0.0054 & 0.49 & 0.4862 \\
\hline$T \times D \times F$ & 1 & 0.0567 & 5.12 & 0.0261 \\
\hline Error & 88 & & & \\
\hline \multicolumn{5}{|l|}{70 days incubation } \\
\hline Tree density $(T)$ & 1 & 2.0897 & 52.34 & 0.0001 \\
\hline Depth(D) & 1 & 0.0064 & 0.16 & 0.6900 \\
\hline Fertilization(F) & 1 & 0.3735 & 9.35 & 0.0029 \\
\hline$T \times D$ & 1 & 0.0002 & 0.00 & 0.9506 \\
\hline $\mathrm{T} \times \mathrm{F}$ & 1 & 0.0467 & 1.17 & 0.2823 \\
\hline$D \times F$ & 1 & 0.0349 & 0.88 & 0.3521 \\
\hline$T \times D \times F$ & 1 & 0.0016 & 0.04 & 0.8433 \\
\hline Error & 88 & & & \\
\hline \multicolumn{5}{|l|}{105 days incubation } \\
\hline Tree density $(T)$ & 1 & 1.3264 & 36.19 & 0.0001 \\
\hline Depth(D) & 1 & 0.0124 & 0.34 & 0.5615 \\
\hline Fertilization(F) & 1 & 0.1183 & 3.23 & 0.0759 \\
\hline$T \times D$ & 1 & 0.1991 & 5.43 & 0.0220 \\
\hline $\mathrm{T} \times \mathrm{F}$ & 1 & 0.0016 & 0.04 & 0.8350 \\
\hline$D \times F$ & 1 & 0.0002 & 0.00 & 0.9476 \\
\hline$T \times D \times F$ & 1 & 0.1072 & 2.93 & 0.0907 \\
\hline Error & 88 & & & \\
\hline
\end{tabular}

However, soil temperature was higher in the low than in the high tree density plots (Table 4). The result suggests that increased cellulose mass loss in the low tree density plots may be attributed to high soil temperature. increased soil temperatures in the low tree density plots were probably due to the increased amount of sunlight reaching the forest floor compared with the high tree density plots. Increased cellulose decomposition rates with high soil temperature were observed in clearcut or partial cutting stands compared with uncut red pine and red oak stands (Kim 2000).

Cellulose filter paper during each sampling time was rapidly

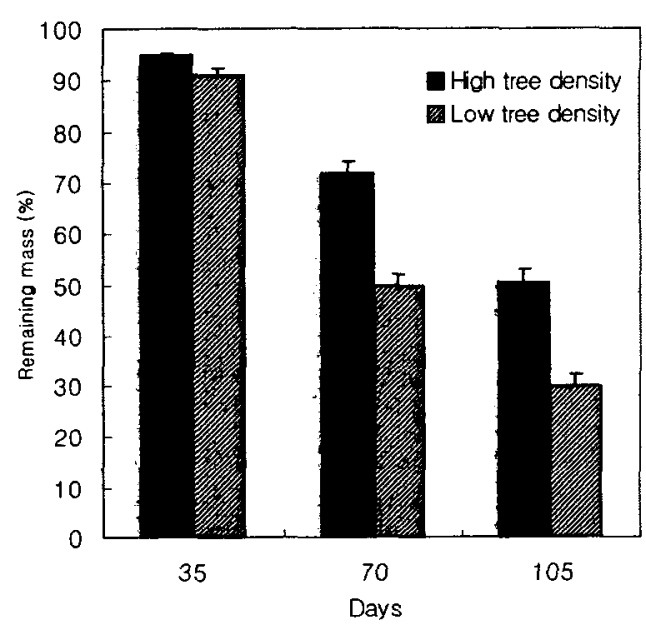

Fig. 1. Mean percent remaining mass over time of cellulose filter papers at different tree density in a Japanese larch plantation. Vertical bars indicate standard error.

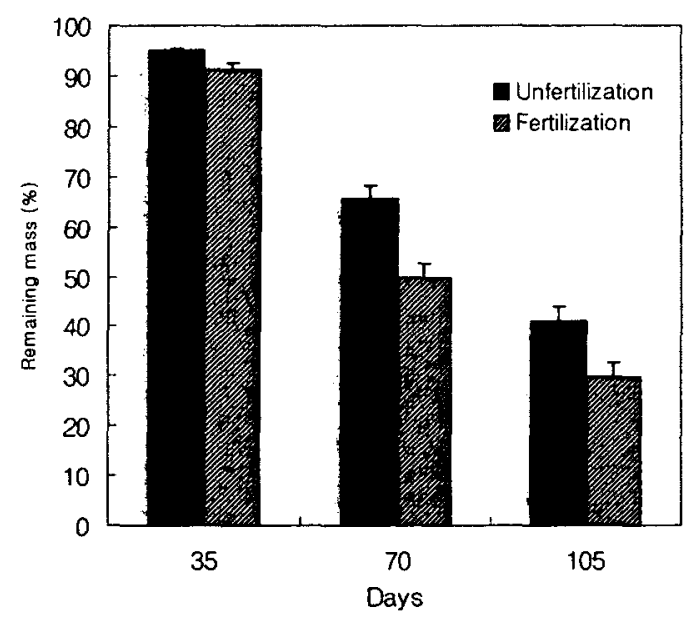

Fig. 2. Mean percent remaining mass over time of cellulose filter papers at fertilization treatments in a Japanese larch plantation. Vertical bars indicate standard error.

decomposed in the fertilization than in the unfertilization treatments (Fig. 2). Cellulose filter papers with fertilization lost $43.6 \%$ 
Table 4. Soil volumetric water content (12cm depth) and soil temperature ( $20 \mathrm{~cm}$ depth) of the study sites (mean $\pm S D, n=16)$

\begin{tabular}{|c|c|c|c|c|}
\hline \multirow{2}{*}{ Date $\quad$ Treatment } & \multicolumn{2}{|c|}{ Tree density } & \multicolumn{2}{|c|}{ Fertilizer } \\
\hline & High & Low & Fertilization & Unfertilization \\
\hline \multicolumn{5}{|l|}{9 August, 2002} \\
\hline Soil water content (\%) & $17.79 \pm 2.72$ & $23.25 \pm 3.00$ & $20.60 \pm 3.46$ & $19.91 \pm 4.65$ \\
\hline Soil temperature $(\mathrm{C})$ & $17.06 \pm 0.66$ & $17.92 \pm 0.29$ & $17.33 \pm 0.72$ & $17.50 \pm 0.65$ \\
\hline \multicolumn{5}{|l|}{6 September, 2002} \\
\hline Soil water content (\%) & $22.38 \pm 7.70$ & $20.94 \pm 5.04$ & $20.06 \pm 4.37$ & $23.25 \pm 7.83$ \\
\hline Soil temperature $\left({ }^{\circ}\right)$ & $17.69 \pm 0.48$ & $19.19 \pm 0.40$ & $18.50 \pm 0.89$ & $18.38 \pm 0.89$ \\
\hline
\end{tabular}

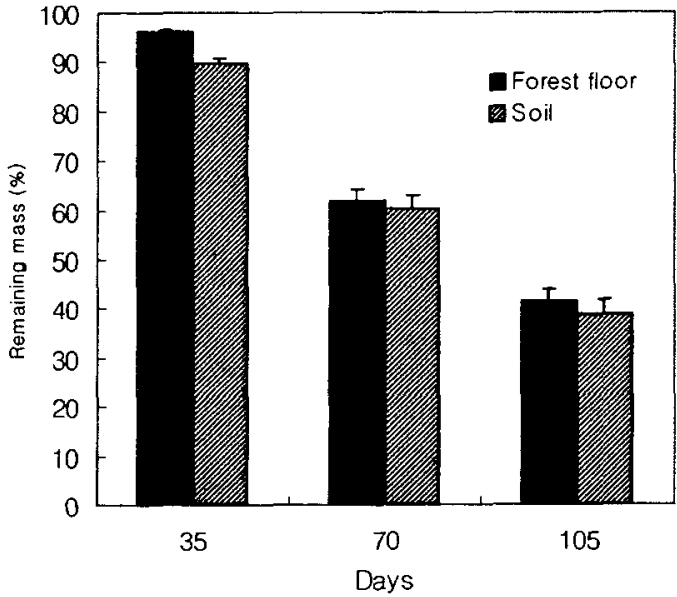

Fig. 3. Mean percent remaining mass over time of cellulose filter papers at the forest floor and the top $15 \mathrm{~cm}$ of mineral soil in a Japanese larch plantation. Vertical bars indicate standard error.

of the original dry mass for 70 days incubation, and cellulose with the unfertilization lost $34.5 \%$ during the same periods. Increased mass loss rates in the fertilization treatment may be due to changes of the activity of soil microflora and fauna with adding fertilizer because of similar site and soil property between treatments (Table 1, 2). There were also no remarkable differences in soil water content and soil temperature between the fertilization and the unfertilization plots during the sampling times (Table 4). It is likely that fertilizer increased the microbial activity under similar climatic and soil conditions. Conn and Day (1996) observed that cellulose filter paper decays significantly faster in response to fertilization in loblolly pine (Pinus taeda), red ceader (Juniperus virginiana) and oak species ecosystems in Virginia, USA. Kim (2000) suggested that cellulose decomposition rates was closely related to increased nitorgen availability after clearcutting oak and pine stands. Beyer (1992) found that cellulose decomposition was lower in spruce stands than in beech stands because of less available $\mathrm{N}$ in the soil solution.

Cellulose mass loss was significantly lower in the forest floor than in the soil layer for 35 days incubation (Table 3, Fig. 3). However, cellulose decomposition rates were not significantly different between the forest floor and the mineral soils after 35 days incubation. In contrast to this result, other studies reported the rapid cellulose mass loss in the forest floor compared with the mineral soils (Donnelly et al. 1990, McClellan et al. 1990).

In summary, the cellulose decomposition rates showed differences corresponding to tree density types and fertilization treatments. Therefore, cellulose decomposition rate is a useful index to express differences in decomposition activity in tree density types and fertilizer treatments.

\section{ACKNOWLEDGEMENTS}

The authors thank Mr. Jang, Kyoung-Su for field assistance. This work was supported by grant No. R05-2002-000-00869-0 from the Basic Research Program of the Korea Science \& Engineering Foundation.

\section{LITERATURE CITED}

Beyer, L. 1992. Cellulolytic activity of Luvisols and Podzols under forest and arable land using the "Cellulose-test" according to Unger. Pedobiologia 36: 137-145.

Binkley, D. 1984. Does forest removal increase rates of decomposition and nitrogen release? For. Ecol. Manage. 8: 229233.

Blair, J. M., R. W. Parmelee and M. H. Beare. 1990. Decay rates, nitrogen fluxes, and decomposer communities of single- and mixed-species foliar litter. Ecology 71: 1976-1985.

Brown, A. H. F. and G. Howson. 1988. Changes in tensile strength loss of cotton strips with season and soil depth under 4 tree species. In A.F. Harrison, P.M. Latter and D. W. H. Walton (eds.), Cotton Strip Assay. an Index of Decomposition in Soils. Institute of Terrestrial Ecology, Grange-over Sands, England. pp. 86-89.

Conn, C. E. and F. P. Day. 1996. Response of root and cotton strip decay to nitrogen amendment along a barrier island dune chronosequence. Can. J. Bot. 74: 276-284.

Donnelly, P. K., J. A. Entry, D. L. Crawford and K. Jr. Cromack. 1990. Cellulose and lignin degradation in forest soils: response to moisture, temperature, and acidity. Microb. Ecol. 
20: $289-295$.

Fogel, R. and K. Cromack. Jr. 1977. Effect of habitat and substrate quality on Douglas fir litter decomposition in western Oregon. Can. J. Bot. 55: 1632-1640.

French, D. D. and G. Howson. 1982. Cellulose decay rates measured by a modified cotton strip method. Soil Biol. Biochem. 14: 311-312.

Hill, M. O., P. M. Latter and G. Bancroft. 1985. A standard curve for inter-site comparison of cellulose degradation using the cotton strip method. Can. J. Soil Sci. 65: 609-619.

Haraguchi, A., H. Kojima, C. Hasegawa, Y. Takahashi, and T lyobe. 2002. Decomposition of organic matter in peat soil in a minerotrophic mire. Euro. J. of Soil Biol. 38:89-95.

Kim, C. 2000. Canopy cover effects on cellulose decomposition in oak and oine stands. J. For. Res. 5: 145-149.

Lousier, J. D. and D. Parkinson. 1976. Litter decomposition in a cool temperate deciduous forest. Can. J. Bot. 54: 419-436.

Mader, S. F., W. M. Aust and R. Lea. 1989. Changes in net primary productivity and cellulose decomposition rates in a water tupelo-bald cypress swamp following timber harvest. In J. H. Miller (ed.), Proceeding of the 5th Biennial Southern
Silvicultural Research Conference. pp. 539-543.

McClellan, M. H., B. T. Bormann and K. Jr. Cromack. 1990 Cellulose decomposition in southeast Alaskan forests: effects of pit and mound microrelif and burial depth. Can. J. For Res. 20: 1242-1246.

Meentemeyer, V. 1978. Macroclimate and lignin control of litter decomposition rates. Ecology 59: 465-472

Neter, J., W. Wasserman and M. H. Kutner. 1990. Applied linear statistical models: Regression, analysis of variance, and statistical designs. 3rd ed. Richard D. Irwin. Homewood. IL. $1181 \mathrm{p}$.

Piene, H. and K. Van Cleve. 1978. Weight loss of litter and cellulose bags in a thinned white spruce forest in interior Alaska. Can. J. For. Res. 8: 42-46.

SAS Institute Inc. 1989. SAS/STAT user's guide. Version 6, 4th ed. Volume 2. Cary, NC. $846 p$.

Yin, X., J. A. Perry and R. K. Dixon. 1989. Influence of canopy removal on oak forest floor decomposition. Can. J. For. Res. 19: 204-214.

(Received November 30, 2002, Accepted December 24, 2002) 